\section{(6) OPEN ACCESS}

\title{
Changes in recreational drug use, drug use associated with chemsex, and HIV-related behaviours, among HIV-negative men who have sex with men in London and Brighton, 2013-2016
}

Janey Sewell, ${ }^{1}$ Valentina Cambiano, ${ }^{1}$ Ada Miltz, ${ }^{1}$ Andrew Speakman, ${ }^{1}$ Fiona C Lampe, Andrew Phillips, ${ }^{1}$ David Stuart, ${ }^{2}$ Richard Gilson, ${ }^{1}$ David Asboe, ${ }^{2}$ Nneka Nwokolo, ${ }^{2}$ Amanda Clarke, ${ }^{3}$ Graham Hart, ${ }^{1}$ Alison Rodger ${ }^{1}$

- Additional material is published online only. To view please visit the journal online (http://dx.doi.org/10.1136/ sextrans-2017-053439).

${ }^{1}$ Research Department of Infection and Population Health, Institute for Global Health, UCL, London, UK

${ }^{2}$ Chelsea and Westminster Hospital NHS Foundation Trust, London, UK

${ }^{3}$ Brighton and Sussex University Hospitals NHS Trust, Brighton, UK

\section{Correspondence to}

Janey Sewell, UCL Institute for Global Health, Royal Free Hospital, London NW3 2PF, UK; j.sewell@ucl.ac.uk

Received 11 October 2017 Revised 5 March 2018 Accepted 18 March 2018 Published Online First 26 April 2018
Check for updates

To cite: Sewell J, Cambiano V, Miltz A, et al. Sex Transm Infect 2018:94:494-501

\section{ABSTRACT}

Objectives The objective of this study was to compare the prevalence of polydrug use, use of drugs associated with chemsex, specific drug use, and HIV-related behaviours, between two time periods, using two groups of HIVnegative men who have sex with men (MSM) attending the same sexual health clinics in London and Brighton, in two consecutive periods of time from 2013 to 2016.

Methods Data from MSM in the cross-sectional Attitudes to and Understanding Risk of Acquisition of HIV (AURAH) study (June 2013 to September 2014) were compared with baseline data from different MSM in the prospective cohort study Attitudes to and Understanding Risk of Acquisition of HIV over Time (AURAH2) (November 2014 to April 2016). Prevalence of polydrug use, drug use associated with chemsex and specific drug use, and 10 measures of HIV-related behaviours including condomless sex, post-exposure prophylaxis (PEP) use, pre-exposure prophylaxis (PrEP) use, and HIV testing, were compared. Prevalence ratios (PRs) for the association of the study (time period) with drug use and HIV-related behaviour measures were estimated using modified Poisson regression analysis, unadjusted and adjusted for sociodemographic factors.

Results In total, 991 MSM were included from AURAH and 1031 MSM from AURAH2. After adjustment for sociodemographic factors, use of drugs associated with chemsex had increased (adjusted PR (aPR) 1.30, 95\% Cl 1.11 to 1.53 ) and there were prominent increases in specific drug use; in particular, mephedrone (aPR 1.32, $95 \% \mathrm{Cl} 1.10$ to 1.57$), \gamma$-hydroxybutyric/ $\gamma$-butryolactone (aPR 1.47, 95\% Cl 1.15 to 1.87 ) and methamphetamine (aPR 1.42, 95\% Cl 1.01 to 2.01). Use of ketamine had decreased (aPR 0.54, 95\% Cl 0.38 to 0.78). Certain measures of HIV-related behaviours had also increased, most notably PEP use (aPR $1.50,95 \% \mathrm{Cl} 1.21$ to 1.88) and number of self-reported bacterial STI diagnoses (aPR $1.24,95 \% \mathrm{Cl} 1.08$ to 1.43 ).

Conclusions There have been significant increases in drug use associated with chemsex and some measures of HIV-related behaviours among HIV-negative MSM in the last few years. Changing patterns of drug use and associated behaviours should be monitored to enable sexual health services to plan for the increasingly complex needs of some clients.

\section{INTRODUCTION}

The use of recreational drugs by gay and bisexual men who have sex with men (MSM) in the UK is significantly higher than in the male population in general. ${ }^{1}$ Along with alcohol and tobacco use, ${ }^{2}$ recreational drug use and its complex relationship with sexual risk behaviour ${ }^{3-5}$ and the potential to facilitate $\mathrm{HIV}^{67}$ and STI transmission ${ }^{89}$ may have a broader impact on the health and well-being of gay men. ${ }^{10} 11$ The emerging phenomenon of chemsex (defined in the UK as the use of mephedrone, crystal methamphetamine and $\gamma$-hydroxybutyric/ $\gamma$-butryolactone $(\mathrm{GHB} / \mathrm{GBL})$ to enable, enhance and prolong sexual interactions ${ }^{12}$ ) is described predominantly within the MSM community, and, although chemsex drug use is not always problematic, ${ }^{13}$ issues relating to it have received increasing academic ${ }^{12} 14$ and clinical $^{15-17}$ attention. The interest is mainly driven by the strong associations with high-risk sexual behaviour ${ }^{517}$ and other potential harms such as overdose and death. ${ }^{18}$ Data from some sexual health clinics suggest there has been a rapid rise in chemsex drug use by MSM attending STI clinics within the last few years, ${ }^{919}$ both in and out of major conurbations, ${ }^{20}$ and chemsex has become a considerable public health concern. Public Health England's 2015/2016 action plan to promote the health and well-being of MSM $^{2}$ and the UK government 2017 Drug Strategy ${ }^{21}$ both target chemsex and aim to reduce it; however, current evidence on prevalence of chemsex drug use is limited, as is the impact chemsex drug use may have on sexual behaviour.

In this paper, we use cross-sectional questionnaire data from two studies that recruited HIV-negative or HIV-undiagnosed MSM from sexual health clinics in England, the Attitudes to and Understanding Risk of Acquisition of HIV (AURAH) study (June 2013 to September 2014), ${ }^{22}$ and the AURAH2 (Attitudes to and Understanding Risk of Acquisition of HIV over Time) study (November 2014 to April 2016). ${ }^{23}$ We assess the prevalence and use of polydrugs, drugs associated with chemsex and specific drug use, and HIV-related behaviours, among the AURAH study participants ${ }^{5}$ and compare it with a different set of participants from the AURAH2 study at a different time period. 


\section{METHODS}

The AURAH study is a cross-sectional, clinic-based study that recruited HIV-negative or undiagnosed participants from sexual health clinics across England between June 2013 and September 2014. ${ }^{22}$ Participants completed a self-administered confidential paper questionnaire on demographics (gender, sexual identity, age, ethnicity, UK birth, English fluency), socioeconomic factors (education, employment, housing, money for basic needs), health and lifestyle factors (alcohol use, smoking, symptoms of depression, treatment for depression and other mental illness), as well as recent sexual behaviour (past 3 months), and recent recreational drug use (past 3 months), while waiting for their clinic appointment (participants were offered a private room if preferred).

The AURAH2 study is a prospective cohort study that recruited HIV-negative or undiagnosed MSM from three of the same sexual health clinics (two in London, one in Brighton) ${ }^{23}$ that participated in the AURAH study. The AURAH2 study used the same paper questionnaire as the AURAH study to collect baseline data, in clinic, during the recruitment period from November 2014 to April 2016. Participants then completed subsequent 4-monthly and annual online questionnaires on HIV status, health and lifestyle factors (including recreational drug use and chemsex) and recent sexual behaviour. Online follow-up of participants continued for 3 years until March 2018 and did not necessitate a clinic visit. Methodological details for both studies, including response rates, have been published elsewhere. ${ }^{22} 23$

This paper uses data collected from the AURAH study and the baseline questionnaire of the AURAH2 study, from MSM aged over 18 and HIV negative (or undiagnosed at recruitment) who attended the three sexual health clinics in England that participated in both the AURAH and the AURAH2 studies: 56 Dean Street, London; Mortimer Market Clinic, London; Claude Nicol Centre, Brighton. Individuals who participated in both studies were only included in the AURAH study analysis for this paper.

\section{Ascertainment of recreational drug use}

All participants were asked to self-report whether they had used recreational drugs in the last 3 months and, if so, to select which drug or drugs from the following list: acid/LSD/magic mushrooms, anabolic steroids, cannabis (marijuana, grass), cocaine (coke), crack, codeine, crystal meth (methamphetamine), ecstasy (E), GHB/GBL (liquid ecstasy), heroin, ketamine (K), khat (chat), mephedrone, morphine, opium, poppers (amyl nitrate), speed (amphetamine), Viagra and Other. If a participant selected 'Other', there was space for free text and a request to specify the name(s) of the drug(s).

\section{Recreational drug use definition}

Two measures of recreational drug use were defined: (1) polydrug use, use of three or more recreational drugs at any time in the past 3 months; (2) drugs associated with chemsex, use of one or more of mephedrone, crystal meth or GHB/GBL in the past 3 months. It should be noted that the questionnaire did not ask about drug use during sex specifically.

\section{HIV-related behaviours}

Ten measures of HIV-related behaviours and related activities were derived from the questionnaire. Four measures of condomless sex (CLS) in the past 3 months were defined as (1) CLS with one or more partners, (2) CLS with two or more partners, (3) CLS with partners of unknown or HIV-positive partners (excluding long-term HIV-positive partners with whom they thought the risks of catching HIV were low because their partner was on antiretroviral therapy) and (4) receptive CLS with an HIV unknown status partner. Six additional measures related to sexual behaviour: (5) diagnosis with a bacterial STI in the past year (gonorrhoea, chlamydia, syphilis and/or lymphogranuloma venereum), (6) more than 11 sexual partners (past year), (7) group sex (in the past 3 months), (8) post-exposure prophylaxis (PEP) use (past year), (9) pre-exposure prophylaxis (PrEP) use (past year) and (10) recent HIV test (past 6 months). CLS refers to anal sex and, for MSM who self-reported their sexuality as bisexual, vaginal sex.

\section{Statistical analysis}

Prevalence of polydrug use, drug use associated with chemsex and specific drug use between the AURAH and AURAH2 study were assessed, with and without adjustment for sociodemographic factors, and results are shown as unadjusted and adjusted prevalence ratios (aPRs). Prevalence of HIV-related behaviours between the two studies (time periods) was then compared with and without adjustment for the same factors. All the multivariable models were adjusted for sociodemographic factors: age (as a continuous variable), ethnicity (born/not born in the UK and white/non-white ethnicity), education (educated to university level or not), sexual identity (gay or bisexual/other) and relationship status (ongoing relationship or not), to produce aPRs using modified Poisson regression analysis. ${ }^{24}$ All analysis was conducted in Stata statistical software V.13. ${ }^{25}$ These models were applied to subjects with no missing values for all the variables included in the model. In sensitivity analyses, we treated missing values as separate categories and applied the models to all subjects in the study.

An additional analysis was undertaken to assess the association of drug use measures with HIV-related behaviours among a restricted sample of AURAH2 MSM that reported anal (or vaginal) sex in the past 3 months to specifically compare those having condom protected sex with those having CLS and the associations with polydrug use and drugs associated with chemsex. The multivariable models were adjusted for (1) the sociodemographic factors outlined above and (2) sociodemographic factors plus higher risk drinking (WHO AUDIT-C (Alcohol Use Disorders Identification Test-C) score $\geq 6$ ) and depressive symptoms PHQ-9 (Patient Health Questionnaire-9) total score $\geq 10$ ).

\section{RESULTS}

\section{Participant characteristics}

In 2013/2014, 1484 MSM participated in the AURAH study. The response rate was $60.0 \% .{ }^{22}$ Of these, $991 \mathrm{MSM}$ attended the same three clinics that took part in the AURAH2 study. There were 1031 individuals who participated in the AURAH2 study with a response rate of $51.2 \%$. In total, 136 individuals participated in both the AURAH and AURAH2 studies and were excluded from the AURAH2 sample for this analysis. Table 1 compares the characteristics of the 991 MSM in the AURAH study with the 1031 MSM who participated in the AURAH2 study. The participant characteristics in both studies were similar: the large majority were white (AURAH 81.0\%, AURAH2 80.5\%), self-identified as gay (AURAH 89.9\%, AURAH2 92.7\%), financially stable (always having money to cover basic needs; AURAH 74.4\%, AURAH2 $76.6 \%$ ), educated to university degree level (AURAH 71.3\%, AURAH2 74.6\%) and employed (AURAH 80.2\%, AURAH2 $82.6 \%$ ) (table 1). The main significant difference between the two studies was the higher proportion of younger MSM $(<25$ years) in the AURAH2 study (AURAH 14.8\%, AURAH2 24.5\%). 
Table 1 Sociodemographic and lifestyle factors of MSM participants in the AURAH and AURAH2 studies

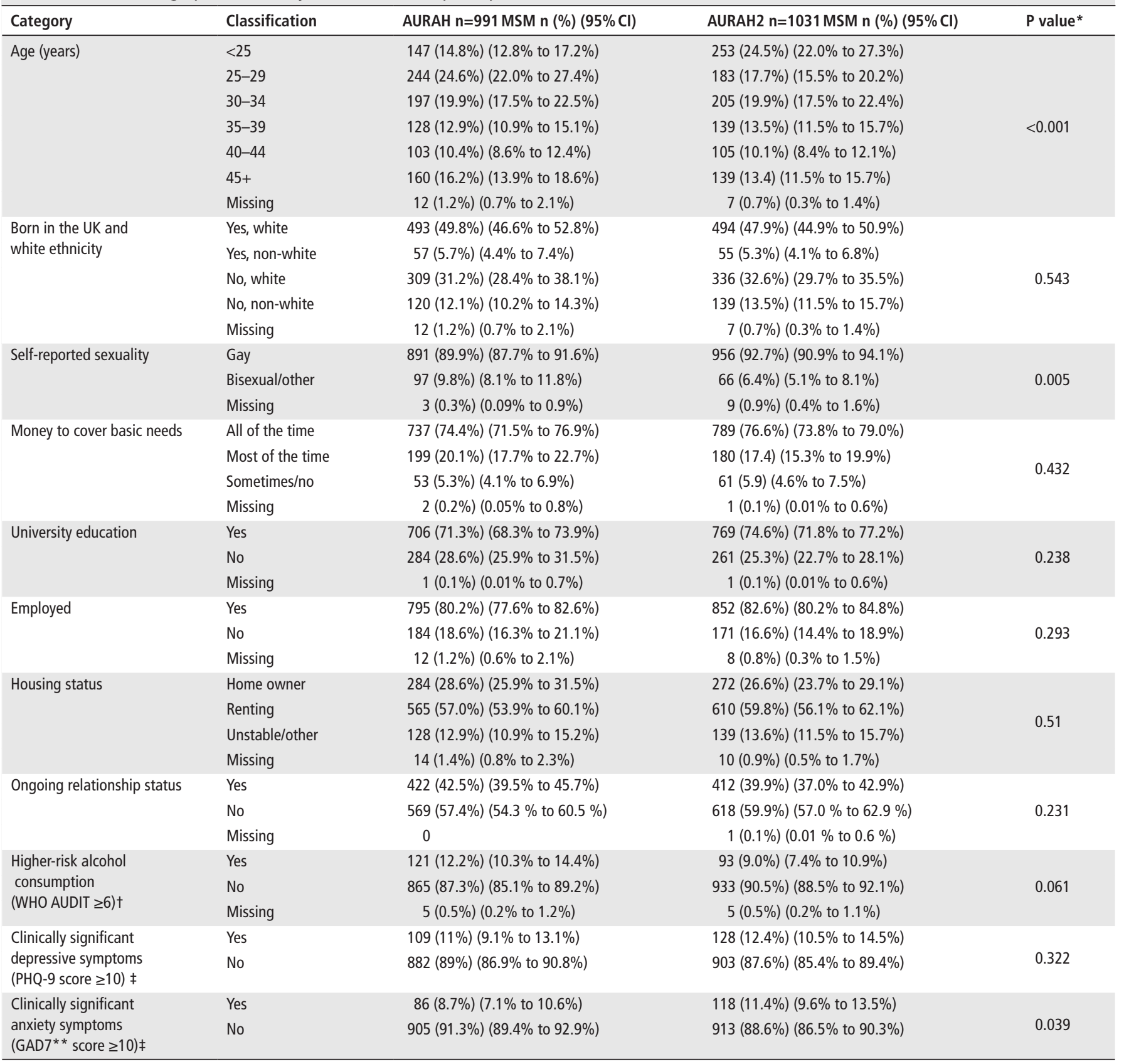

${ }^{*} \mathrm{P}$ value by $\chi^{2}$ test or Fisher's exact test where appropriate.

tHigher-risk drinking is based on the first three questions of the WHO AUDIT-C questionnaire. Higher-risk drinking is indicated by a score of $\geq 6$ and lower-risk drinking/no alcohol consumption by a score of $<6$.

$\ddagger$ All included participants completed at least one answer in this section of the questionnaire, providing a minimum score of at least 1.

* * GAD7 (Generalised Anxiety Disorder-7)

AURAH, Attitudes to and Understanding Risk of Acquisition of HIV; AURAH2, Attitudes to and Understanding Risk of Acquisition of HIV over Time; MSM, men who have sex with men.

\section{Changes over time in recreational drug use}

Overall, a greater proportion of MSM in the AURAH2 study reported use of one or more recreational drug(s) in the past 3 months (AURAH 57.4\%, AURAH2 60.4\%). Figure 1 shows the proportion of MSM reporting polydrug use, the use of drugs associated with chemsex, and specific, individual drugs used in the AURAH and AURAH2 study. There was an increase in polydrug use from the AURAH to AURAH2 study (PR 1.19, 95\% CI 1.04 to $1.37, \mathrm{P}=0.01$ ); however, after adjustment for sociodemographic factors, the increase did not persist (aPR
$1.16,95 \% \mathrm{CI} 0.99$ to $1.37, \mathrm{P}=0.07)$. The use of drugs associated with chemsex had significantly increased by about a third from AURAH to AURAH2, and this increase remained significant after adjustment for sociodemographic factors (aPR 1.30, 95\% CI 1.11 to $1.53, \mathrm{P}=0.002$ ) (see figure 1 ).

Across both studies, the most commonly used drug was nitrites (AURAH 35.2\%, AURAH2 36.3\%) (figure 1). The prevalence of cocaine use (AURAH 21.5\%, AURAH2 23.9\%), cannabis (AURAH 20.9\%, AURAH2 20.1\%) and MDMA (AURAH 14.1\%, AURAH2 14.5\%) was similar between the two studies (figure 1). 


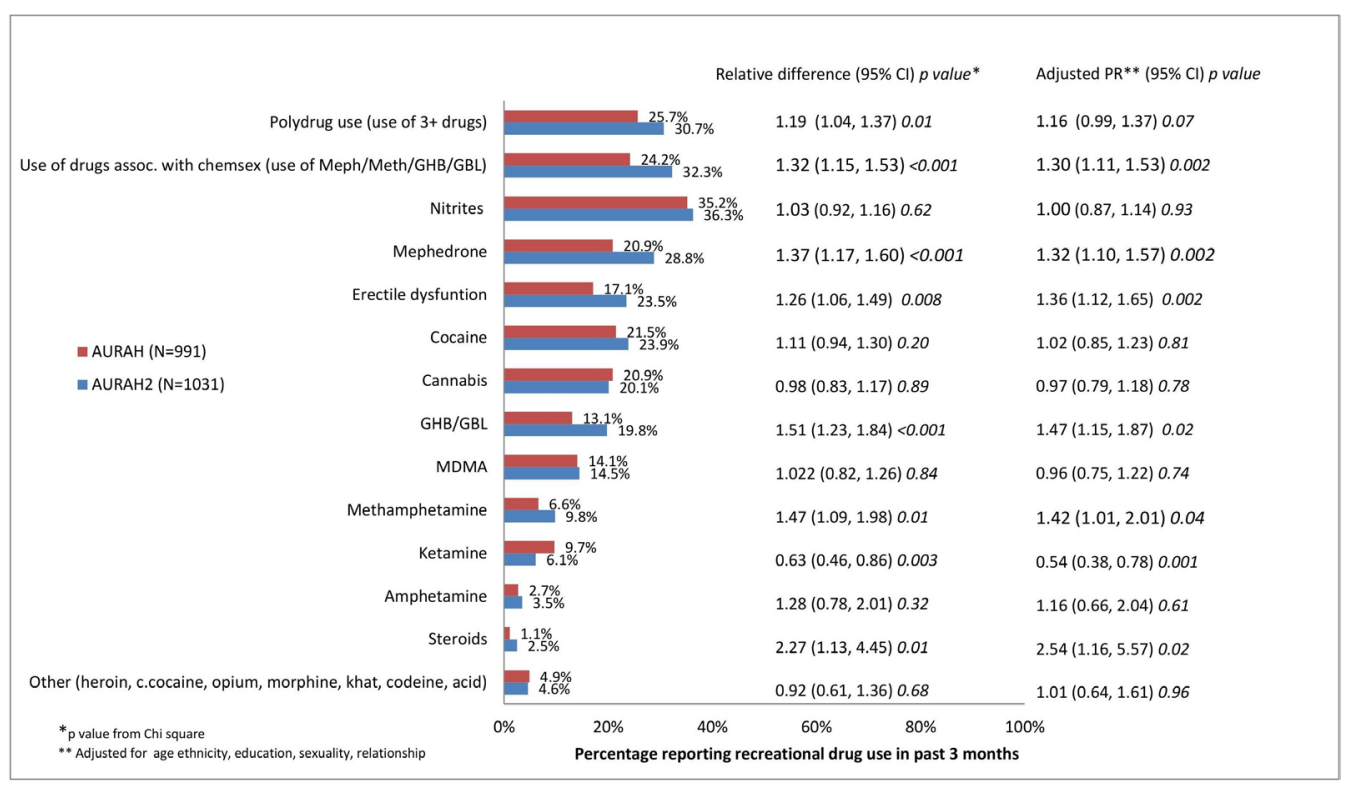

Figure 1 Prevalence of polydrug use, drug use associated with chemsex and individual drug use in MSM participants in the Attitudes to and Understanding Risk of Acquisition of HIV (AURAH, 2013-14) and Attitudes to and Understanding Risk of Acquisition of HIV over Time (AURAH2, 201416) studies.

The most prominent increases in the use of specific drugs were seen in drugs associated with chemsex; mephedrone use had increased by about a third (aPR $1.32,95 \%$ CI 1.10 to 1.57 ), GHB/GBL by nearly half (aPR $1.47,95 \%$ CI 1.15 to 1.87 ) and methamphetamine use had increased by nearly half (aPR 1.42, 95\% CI 1.01 to 2.01). In fact, use of nearly all types of specific drugs had increased in the AURAH2 study with the exception of ketamine, which had decreased (aPR 0.54, 95\% CI 0.38 to 0.78 ), while cannabis and 'other drugs' (heroin, crack cocaine, opium, morphine, khat, codeine, acid) remained at roughly the same prevalence. The proportion of MSM who reported use of drugs associated with chemsex, while still a minority, had increased from the AURAH to AURAH2 study for all three drugs commonly associated with chemsex: mephedrone from $20.9 \%$ to $28.8 \%, \mathrm{GHB} / \mathrm{GBL}$ from $13.1 \%$ to $19.8 \%$ and methamphetamine $6.6 \%$ to $9.8 \%$ (see figure 1 ).

\section{Changes over time in HIV-related behaviours}

Some measures of HIV-related behaviours had increased to various extents in the AURAH2 study compared with the AURAH study (CLS, CLS 2+ partners, STI, PEP, PreP, HIV testing), and most of these remained statistically significant after adjusting for sociodemographic factors (table 2).

The results were very similar when missing values for all the variables included in the model were treated as separate categories and applied (see online supplementary table 4).

The largest differences among the measures of HIV-related behaviours between the AURAH and AURAH2 study was in PEP use (past year), which had increased by over $40 \%$ (aPR 1.50 , $95 \%$ CI 1.21 to 1.88 ), and the number of self-reported bacterial STI diagnoses (past year), which had increased by a quarter (aPR 1.24, 95\% CI 1.08 to 1.43). There was also an increase in the proportion of men who had recently tested for HIV in the AURAH2 study, which remained significant after adjustment for study and sociodemographic factors (aPR 1.14, 95\% CI 1.07 to 1.21$)$.

\section{Relationship between recreational drug use and HIV-related behaviours}

Table 3 shows the associations of polydrug use and drug use associated with chemsex, with HIV-related behaviour measures among the subgroup of MSM who reported anal (or vaginal) sex within the past 3 months $(n=949)$ in the AURAH2 study. Similar to the AURAH study results, ${ }^{5}$ in AURAH2, polydrug and drug use associated with chemsex use remained strongly associated with all measures of HIV-related behaviours, with the exception of receptive CLS with unknown status partner, in (1) unadjusted, (2) adjusted for study, age, ethnicity, sexual identity, university education and ongoing relationship status, and (3) adjusted for study, sociodemographic factors plus additional, higher-risk drinking and depressive symptoms.

\section{DISCUSSION}

We observed substantial increases over the 3-year period from the AURAH to AURAH2 study in the use of drugs associated with chemsex and specific drug use, as well as increases in some measures of HIV-related behaviours, including condomless sex, PEP, - and HIV testing . The most notable increase was the prevalence of drugs associated with chemsex (AURAH: 24.2\% vs AURAH2: $32.3 \%$ ), driven by the considerable individual increases in mephedrone, methamphetamine and $\mathrm{GHB} /$ GBL. Certain measures of HIV-related behaviours had also increased, including CLS with one or more partners, which may partly explain the increase in self-reported bacterial STI diagnosis from the AURAH to AURAH2 study (30.5\% vs 3\%). Encouragingly, there was also an increase in the number of MSM who reported an HIV test in the past 6 months (63.8\% vs 73.4\%), in line with increasing ever and repeat HIV testing in MSM in the UK over the same time period. ${ }^{26}$

To our knowledge, the AURAH and AURAH2 studies are the largest studies within the UK to have investigated prevalence of recreational drug use and HIV-related behaviours among HIV-negative MSM attending sexual health clinics. The prevalence of recreational and specific drug use in our results from 
Table 2 Prevalence of HIV-related behaviours among men who have sex with men in the Attitudes to and Understanding Risk of Acquisition of HIV (AURAH) $(n=991)$ and Attitudes to and Understanding Risk of Acquisition of HIV over Time (AURAH2) ( $n=1031)$ studies and association of these measures with study

\begin{tabular}{|c|c|c|c|c|c|c|}
\hline Measures of sexual behaviour & Study & Prevalence $\mathrm{n}(\%)(95 \% \mathrm{Cl})$ & $\begin{array}{l}\text { Unadjusted PR }(95 \% \mathrm{Cl}) \\
\text { AURAH2 vs AURAH* }\end{array}$ & $P$ valuet & Adjusted $¥$ PR $(95 \% \mathrm{Cl})$ & $P$ valuet \\
\hline \multirow{2}{*}{$\begin{array}{l}\text { CLS with one or more partners } \\
\text { (past } 3 \text { months) }\end{array}$} & AURAH & $558(56.3 \%)(53.3 \%$ to $59.4 \%)$ & \multirow[t]{2}{*}{1.14 (1.07 to 1.23$)$} & \multirow[t]{2}{*}{$<0.001$} & \multirow[t]{2}{*}{1.14 (1.05 to 1.24$)$} & \multirow{2}{*}{0.001} \\
\hline & AURAH2 & $664(64.4 \%)(61.5 \%$ to $67.4 \%)$ & & & & \\
\hline \multirow{2}{*}{$\begin{array}{l}\text { CLS with two or more partners } \\
\text { (past } 3 \text { months) }\end{array}$} & AURAH & $286(28.8 \%)(26.1 \%$ to $31.8 \%)$ & \multirow[t]{2}{*}{1.22 (1.08 to 1.39$)$} & \multirow[t]{2}{*}{0.002} & \multirow[t]{2}{*}{$1.22(1.05$ to 1.41$)$} & \multirow{2}{*}{0.008} \\
\hline & AURAH2 & $365(35.4 \%)(32.5 \%$ to $38.4 \%)$ & & & & \\
\hline \multirow{2}{*}{$\begin{array}{l}\text { CLS with unknown/HIV+ status } \\
\text { partner(s) (past } 3 \text { months) }\end{array}$} & AURAH & $310(31.3 \%)(28.5 \%$ to $34.3 \%)$ & \multirow[t]{2}{*}{1.00 (0.88 to 1.14$)$} & \multirow[t]{2}{*}{0.944} & \multirow[t]{2}{*}{0.99 (0.85 to 1.14$)$} & \multirow{2}{*}{0.893} \\
\hline & AURAH2 & $324(31.4 \%)(28.7 \%$ to $34.3 \%)$ & & & & \\
\hline \multirow{2}{*}{$\begin{array}{l}\text { Receptive CLS with unknown HIV } \\
\text { status partner(s) (past } 3 \text { months) }\end{array}$} & AURAH & $116(11.7 \%)(9.8 \%$ to $13.8 \%)$ & \multirow[t]{2}{*}{1.06 (0.84 to 1.34$)$} & \multirow[t]{2}{*}{0.624} & \multirow[t]{2}{*}{0.98 (0.75 to 1.28$)$} & \multirow{2}{*}{0.901} \\
\hline & AURAH2 & $128(12.4 \%)(10.5 \%$ to $14.6 \%)$ & & & & \\
\hline \multirow{2}{*}{$\begin{array}{l}\text { Self-reported bacterial STI } \\
\text { diagnosis (past year) }\end{array}$} & AURAH & $303(30.5 \%)(27.8 \%$ to $33.5 \%)$ & \multirow[t]{2}{*}{1.30 (1.15 to 1.47$)$} & \multirow[t]{2}{*}{$<0.001$} & \multirow[t]{2}{*}{1.24 (1.08 to 1.43$)$} & \multirow{2}{*}{0.002} \\
\hline & AURAH2 & $411(39.8 \%)(36.9 \%$ to $42.9 \%)$ & & & & \\
\hline \multirow{2}{*}{$\begin{array}{l}\text { Eleven or more new sexual } \\
\text { partners (past year) }\end{array}$} & AURAH & $374(37.7 \%)(34.8 \%$ to $40.1 \%)$ & \multirow[t]{2}{*}{1.07 (0.97 to 1.20$)$} & \multirow[t]{2}{*}{0.168} & \multirow[t]{2}{*}{1.11 (0.98 to 1.25$)$} & \multirow{2}{*}{0.09} \\
\hline & AURAH2 & $420(40.7 \%)(37.8 \%$ to $43.7 \%)$ & & & & \\
\hline \multirow[t]{2}{*}{ Group sex (past 3 months) } & AURAH & $388(39.1 \%)(36.2 \%$ to $42.2 \%)$ & \multirow[t]{2}{*}{1.10 (0.99 to 1.22$)$} & \multirow[t]{2}{*}{0.069} & \multirow[t]{2}{*}{1.10 (0.97 to 1.24$)$} & \multirow{2}{*}{0.08} \\
\hline & AURAH2 & 438 (42.5\%) (39.5\% to $45.5 \%)$ & & & & \\
\hline PEP use (past year) & AURAH & $151(15.2 \%)(13.1 \%$ to $17.6 \%)$ & 1.43 (1.18 to 1.72$)$ & $<0.001$ & 1.50 (1.21 to 1.88$)$ & $<0001$ \\
\hline & AURAH2 & $224(21.7 \%)(19.3 \%$ to $24.4 \%)$ & & & & $<0.001$ \\
\hline PrEP use (past year) & AURAH & $38(3.8 \%)(2.5 \%$ to $4.5 \%)$ & 1.44 (0.96 to 2.15$)$ & 0.074 & 1.31 (0.70 to 1.82$)$ & 0.611 \\
\hline & AURAH2 & $57(5.5 \%)(4.3 \%$ to $7.1 \%)$ & & & & 0.011 \\
\hline Recent HIV test (past 6 months) & AURAH & $631(63.8 \%)(60.7 \%$ to $66.7 \%)$ & 1.15 (1.09 to 1.22$)$ & $<0.001$ & $1.14(1.07$ to 1.21$)$ & 00 \\
\hline & AURAH2 & $757(73.4 \%)(70.6 \%$ to $76.0 \%)$ & & & & $<0.001$ \\
\hline
\end{tabular}

${ }^{*}$ AURAH is the reference group.

${ }^{\dagger} \mathrm{P}$ value by Wald test.

¥Adjusted model (ii) study, age (continuous variable), ethnicity, sexual identity, university education, ongoing relationship status (Poisson model on subject with no missing values for all the variables included in the model).

AURAH, Attitudes to and Understanding Risk of Acquisition of HIV; AURAH2, Attitudes to and Understanding Risk of Acquisition of HIV over Time; CLS, condomless sex; PEP, postexposure prophylaxis; PR, prevalence ratio; PrEP, pre-exposure prophylaxis.

the AURAH study is similar to that reported by other high-income countries from the same calendar years, ${ }^{27} 28$ however the AURAH2 study results provide a more recent estimate. In Australia, baseline analysis on the first entirely online cohort study of MSM (Following Lives Undergoing Change (Flux) study) $(n=2250)$ recruited in 2014/2015, found that over half $(50.5 \%)$ had reported use of any illicit drug in the previous 6 months, and over a quarter $(28 \%)$ had used party drugs (E, speed, cocaine, crystal methamphetamine, GHB, ketamine, LSD) in the previous 6 months. ${ }^{27}$ Trends in drug use among Australian gay men are also monitored in routinely conducted behavioural surveillance surveys, 'the Gay Community Periodic Surveys', which suggest little change in recent years. ${ }^{29}$ A similar- prevalence $(55.7 \%)$ was reported among HIV-negative MSM in the USA by the National HIV Behavioural Surveillance survey conducted in the same year as the AURAH and Flux studies (2014), ${ }^{28}$ and this has steadily increased among MSM (regardless of HIV status) from $43 \%$ in $2004 / 2005^{30}$ to $49 \%$ in $2011,{ }^{31}$ to $55.7 \%{ }^{28}$ in 2014 . As demonstrated by the changes in prevalence and patterns of drug use and associated behaviours over time in our results, the monitoring of recreational drug use in MSM is vital if service providers, including sexual health, HIV and drug use services, are to anticipate and plan for the needs of their clients, whilst a better understanding of factors that may facilitate the use of drugs within a sexual setting, such as geospatial networking apps, ${ }^{32}$ is needed. Furthermore, longitudinal monitoring could help identify trends that may be hidden when examining prevalences in cross-sectional surveys.

A recent steep decline in HIV diagnoses has been reported in two of the London clinics from which the AURAH and AURAH2 studies recruited, ${ }^{26}$ despite an increase in HIV testing. The decline in HIV incidence has been attributed to a combination of prevention interventions, particularly testing followed by rapid initiation of HIV treatment, and the use of PrEP (despite not being freely available). ${ }^{26}$ Self-reported PrEP use was relatively low in in both AURAH (3.8\%) and AURAH2 (5.5\%), although it is likely to have increased since the collection of the AURAH2 baseline. In the USA, where PrEP has been available since 2012, HIV-negative MSM substance users were identified as a highrisk trajectory group that would benefit from access to PrEP, ${ }^{33}$ and our results indicate that this is similar in the UK. While the effect of wider access to PrEP on sexual behaviour and recreational drug use is yet unknown, our results show an increasing trend in certain measures of HIV-related behaviours and polydrug and recreational drug use in a context where PrEP is not freely available.

MSM who use recreational drugs, particularly in the context of chemsex, may not see themselves as 'typical' drug misusers or consider the use of chemsex drugs to be problematic and are therefore unlikely to access traditional drug services. ${ }^{32}$ Equally, these services may not be trained to deal with the specific needs of this population. ${ }^{15}$ The large numbers of MSM reporting polydrug use and drugs associated with chemsex in the AURAH and AURAH2 studies, along with the high proportions of PEP use, STI infection and clinically significant depression and anxiety symptoms, highlight the complex needs of this population and support the view that sexual health services need to provide holistic clinical assessment and care, including drug services, to improve health and well-being in an acceptable environment for MSM. ${ }^{16} 17$ 
Table 3 Associations of polydrug use and drug use associated with chemsex, with measures of HIV-related behaviours, among 949 MSM in the AURAH2 study who reported anal or vaginal sex in the past 3 months

\begin{tabular}{|c|c|c|c|c|c|c|}
\hline \multirow[b]{2}{*}{$\begin{array}{l}\text { HIV-related behaviour } \\
\text { outcome }\end{array}$} & \multicolumn{3}{|c|}{ Poly drug use (past 3 months) } & \multicolumn{3}{|c|}{ Chemsex drug use (past 3 months) } \\
\hline & $\begin{array}{l}\text { Unadjusted } \\
\text { PR }(95 \% \mathrm{Cl}) \\
\text { P value* }\end{array}$ & $\begin{array}{l}\text { Adjusted (i) } \\
\text { PR }(95 \% \mathrm{CI}) \\
\text { P value* }\end{array}$ & $\begin{array}{l}\text { Adjusted (ii) } \\
\text { PR }(95 \% \mathrm{Cl}) \\
\text { P value* }\end{array}$ & $\begin{array}{l}\text { Unadjusted } \\
\text { PR }(95 \% \mathrm{CI}) \\
\text { P value* }\end{array}$ & $\begin{array}{l}\text { Adjusted (i) } \\
\text { PR }(95 \% \mathrm{Cl}) \\
\text { P value* }\end{array}$ & $\begin{array}{l}\text { Adjusted (ii) } \\
\text { PR }(95 \% \mathrm{Cl}) \\
\text { P value* }\end{array}$ \\
\hline \multirow{2}{*}{$\begin{array}{l}\text { CLS with one or more } \\
\text { partners (past } 3 \text { months) }\end{array}$} & 1.30 (1.20 to 1.40$)$ & 1.31 (1.21 to 1.42$)$ & $1.31(1.21$ to 1.41$)$ & $1.32(1.23$ to 1.43$)$ & 1.33 (1.23 to 1.44$)$ & 1.33 (1.23 to 1.44$)$ \\
\hline & $<0.001$ & $<0.001$ & $<0.001$ & $<0.001$ & $<0.001$ & $<0.001$ \\
\hline \multirow{2}{*}{$\begin{array}{l}\text { CLS with two or more } \\
\text { partners (past } 3 \text { months) }\end{array}$} & 1.91 (1.64 to 2.24$)$ & 1.93 (1.65 to 2.25$)$ & 1.91 (1.63 to 2.23$)$ & 1.95 (1.67 to 2.28$)$ & 1.95 (1.67 to 2.28$)$ & 1.94 (1.66 to 2.27$)$ \\
\hline & $<0.001$ & $<0.001$ & $<0.001$ & $<0.001$ & $<0.001$ & $<0.001$ \\
\hline \multirow{2}{*}{$\begin{array}{l}\text { CLS with unknown/HIV- } \\
\text { positive partner } \\
\text { (past } 3 \text { months) }\end{array}$} & 1.71 (1.44 to 2.03 ) & 1.69 (1.43 to 2.02$)$ & 1.71 (1.43 to 2.03$)$ & 1.83 (1.54 to 2.17$)$ & 1.81 (1.52 to 2.16$)$ & 1.82 (1.53 to 2.16$)$ \\
\hline & $<0.001$ & $<0.001$ & $<0.001$ & $<0.001$ & $<0.001$ & $<0.001$ \\
\hline \multirow{2}{*}{$\begin{array}{l}\text { Receptive CLS with } \\
\text { unknown status partner } \\
\text { (past } 3 \text { months) }\end{array}$} & 1.37 (0.98 to 1.89$)$ & $1.34(0.97$ to 1.87$)$ & $1.34(0.97$ to 1.85$)$ & $1.36(0.98$ to 1.89$)$ & 1.34 (0.97 to 1.86$)$ & $1.34(0.97$ to 1.85$)$ \\
\hline & 0.062 & 0.07 & 0.08 & 0.07 & 0.08 & 0.08 \\
\hline \multirow{2}{*}{$\begin{array}{l}\text { Bacterial STI diagnosis } \\
\text { (past year) }\end{array}$} & 1.65 (1.43 to 1.91$)$ & $1.66(1.44$ to 1.91$)$ & $1.66(1.43$ to 1.91$)$ & $1.69(1.43$ to 1.91$)$ & $1.66(1.43$ to 1.91$)$ & $1.65(1.43$ to 1.91$)$ \\
\hline & $<0.001$ & $<0.001$ & $<0.001$ & $<0.001$ & $<0.001$ & $<0.001$ \\
\hline \multirow{2}{*}{$\begin{array}{l}\text { Eleven or more new } \\
\text { sexual partners } \\
\text { (past year) }\end{array}$} & 1.64 (1.43 to 1.89$)$ & $1.62(1.41$ to 1.86$)$ & 1.61 (1.39 to 1.85$)$ & 1.61 (1.39 to 1.85$)$ & 1.56 (1.36 to 1.79$)$ & 1.55 (1.35 to 1.78$)$ \\
\hline & $<0.001$ & $<0.001$ & $<0.001$ & $<0.001$ & $<0.001$ & $<0.001$ \\
\hline \multirow{2}{*}{$\begin{array}{l}\text { Group sex } \\
\text { (past } 3 \text { months) }\end{array}$} & 2.41 (2.11 to 2.75 ) & 2.38 (2.08 to 2.72 ) & 2.38 (2.09 to 2.73 ) & 2.39 (2.09 to 2.75$)$ & 2.39 (2.09 to 2.74 ) & 2.39 (2.09 to 2.74$)$ \\
\hline & $<0.001$ & $<0.001$ & $<0.001$ & $<0.001$ & $<0.001$ & $<0.001$ \\
\hline \multirow{2}{*}{ PEP use (past year) } & $2.16(1.72$ to 2.71$)$ & 2.15 (1.71 to 2.71$)$ & 2.16 (1.72 to 2.72$)$ & 2.47 (1.95 to 3.11$)$ & 2.43 (1.93 to 3.08$)$ & 2.44 (1.93 to 3.08$)$ \\
\hline & $<0.001$ & $<0.001$ & $<0.001$ & $<0.001$ & $<0.001$ & $<0.001$ \\
\hline \multirow{2}{*}{ PrEP use (past year) } & 2.46 (1.49 to 4.01$)$ & 2.54 (1.54 to 4.19$)$ & 2.69 (1.64 to 4.43$)$ & 2.13 (1.29 to 3.52$)$ & 2.28 (1.39 to 3.71$)$ & 2.38 (1.46 to 3.86$)$ \\
\hline & $<0.001$ & $<0.001$ & $<0.001$ & 0.003 & 0.001 & $<0.001$ \\
\hline \multirow{2}{*}{$\begin{array}{l}\text { Recent HIV test (within } \\
\text { past } 6 \text { months) }\end{array}$} & 1.16 (1.08 to 1.25$)$ & 1.16 (1.08 to 1.25$)$ & 1.17 (1.09 to 1.26$)$ & 1.18 (1.10 to 1.26$)$ & 1.18 (1.10 to 1.27$)$ & $1.18(1.11$ to 1.27$)$ \\
\hline & $<0.001$ & $<0.001$ & $<0.001$ & $<0.001$ & $<0.001$ & $<0.001$ \\
\hline
\end{tabular}

Adjusted model (i) age (continuous variable), ethnicity, sexual identity, university education, ongoing relationship status.

Adjusted model (ii) age (continuous variable), ethnicity, sexual identity, university education, ongoing relationship status, higher-risk drinking, depressive symptoms (PHQ-9 $\geq 10$ ) (missing values included in variables for adjusted models).

${ }^{*} P$ values by Wald test.

AURAH2, Attitudes to and Understanding Risk of Acquisition of HIV over Time; CLS, condomless sex; MSM, men who have sex with men; PEP, post-exposure prophylaxis; PrEP, pre-exposure prophylaxis.

\section{Limitations}

We recognise the different proportions in non-response between the AURAH and AURAH2 study could bias the comparison, and unfortunately data were not collected on the characteristics of non-responders to limit this. We also acknowledge a certain degree of selection bias may have occurred during recruitment to both studies. We further recognise that in our results, the reporting of drugs associated with chemsex does not necessarily equate to use of drugs during sex; however, previous data have shown that $75 \%$ of mephedrone and $85 \%$ of $\mathrm{GHB} / \mathrm{GBL}$ users said they used the drugs solely to facilitate sex, ${ }^{32}$ although the use of drugs outside of a sexual setting, such as in a social or clubbing environment, is also important to consider. Additionally, the results from the AURAH and AURAH2 studies may not be directly generalisable to the broader MSM population due to the sample of men being solely from sexual health clinics in London and Brighton, which have large gay communities, and may not reflect behaviour and lifestyle choices of clinic attendees in the wider community. In contrast to non-clinic attendees, and given the strong associations between sexual behaviour and recreational drug use, MSM who voluntarily attend sexual health clinics may have self-identified a need for sexual health screening, which could explain the associated higher prevalence of recreational drug use in this group. Furthermore, two of the clinics that participated in the AURAH and AURAH2 studies, 56 Dean Street and Mortimer Market Clinic, are specialist centres of chemsex support where chemsex awareness is robust and specific psychosocial interventions are offered frequently to high-risk MSM. The increased awareness and community engagement around chemsex within these two clinics may have resulted in a larger proportion of those engaging in chemsex opting to attend them, which may also account for an overestimation. However, it is also possible that some MSM not engaged with clinics may not test for HIV and STIs through perceived stigma or fear related to higher-risk sexual behaviours and or recreational drug use, and therefore our results could potentially underestimate the true prevalence of both.

\section{CONCLUSIONS}

There have been significant changes in use of drugs associated with chemsex and specific drug use, as well as increases across measures of HIV-related behaviours among HIV-negative MSM in the AURAH and AURAH2 study. Despite the decline in HIV

\section{Key messages}

- Use of drugs associated with chemsex has substantially increased among HIV-negative men who have sex with men attending sexual health clinics from 2013 to 2016.

- Some measures of HIV-related behaviours including condomless sex, post-exposure prophylaxis, and HIV testing have also increased between 2013 and 2016.

- There is a need for improved monitoring to assess changing patterns of recreational drug use and associated behaviours so that sexual health services are able to anticipate and provide holistic care for their clients. 
diagnoses in some London clinics, our results demonstrate the increasingly complex needs of MSM attending clinics for sexual healthcare, lifestyle support and health promotion. There remains a clear need for investment to adequately resource and support sexual health clinics to collaborate with specialised drug services to provide appropriate care that encompasses recreational drug use as well as sexual health.

\section{Handling editor Jane S Hocking}

Acknowledgements We would like to thank all the study participants for their time and effort. We gratefully acknowledge the contributions of all the AURAH and AURAH2 clinic teams who helped with data collection, distribution of questionnaires and administrative tasks. We gratefully acknowledge the three participating sites and the contributions and efforts of the following at each site: The Mortimer Market Centre, London: AURAH: Richard Gilson, Ana Milinkovic, Clare Oakland, Rita Trombin, AURAH2: Richard Gilson, Ana Milinkovic, Fabienne Styles, Rosanna Laverick, Marzena Orzol, Emmi Suonpera. 56 Dean Street Clinic, London: AURAH and AURAH2: Nneka Nwokolo, Ali Ogilvy. The Claude Nicol Centre, Brighton: AURAH: Martin Fisher, Amanda Clarke, Nicky Perry, Elaney Youssef, Celia Richardson, Louise Kerr, Mark Roche, David Stacey, Sarah Kirk, AURAH2: Amanda Clarke, Nicky Perry, Elaney Youssef, Celia Richardson, Sarah Kirk, Marion Campbell, Lisa Barbour. AURAH/AURAH2 (core) Study Group: Alison Rodger, Fiona Lampe, Andrew Phillips and Andrew Speakman. AURAH and AURAH2 data managers: Andrew Speakman, Janey Sewell and Ada Miltz. AURAH/AURAH2 study nurse coordinator: Janey Sewell. AURAH advisory board: Lorraine Sherr, Graham Hart, Simon Collins, Anne Johnson, Alec Miners and Jonathan Elford. AURAH2 advisory board: Lorraine Sherr, Graham Hart, ValerieDelpech, Simon Collins, Anne Johnson, Susan Michie, Jonathan Elford. The AURAH and AURAH2 Study Group acknowledges the support of the NIHR through the Comprehensive Clinical Research Network.

Contributors Design and data collection: JS, AS, AP, DS, FL, RG, DA, NN, AC, GH, AR. Analysis and interpretation: JS, VC, AR. Drafting the manuscript: JS, VC, AM, FCL, $A S, A P, A R$.

Funding Thsi manuscript summarises independent research funded by the National Institute for Health Research (NIHR) under its Programme Grants for Applied Research Programme (Grant Reference Numbers RP-PG-1212-20006 [AURAH2] and RP-PG-0608-10142 [AURAH]). The views expressed are those of the authors and not necessarily those of the NHS, the NIHR or the Department of Health. The AURAH and AURAH2 study were sponsored by the Joint Research Office, UCL. The sponsor of the study had no role in design and conduct of the study; collection, management, analysis and interpretation of the data; preparation, review or approval of the manuscript; and decision to submit the manuscript for publication.

Disclaimer The views expressed in this presentation are those of the authors and not necessarily those of the NHS, the NIHR or the Department of Health.

\section{Competing interests None declared.}

Ethics approval The AURAH study received ethics approval from NRES committee London-Hampstead, ref: 13/LO/0246 in April 2014. The AURAH2 study was approved by the designated research ethics committee, NRES committee LondonHampstead, ref: 14/LO/1881 in November 2014. Based on these documents, the studies subsequently received permission for clinical research at the three participating National Health Service sites: Chelsea and Westminster NHS Foundation Trust, Central and North West London NHS Foundation Trust, and the Brighton and Sussex University Hospitals NHS Trust. All participants provided written, informed consent before taking part.

Provenance and peer review Not commissioned; externally peer reviewed.

Data sharing statement Supplementary data on missing data (from table 2) have been submitted to this journal and are available upon request.

Open access This is an open access article distributed in accordance with the Creative Commons Attribution Non Commercial (CC BY-NC 4.0) license, which permits others to distribute, remix, adapt, build upon this work non-commercially, and license their derivative works on different terms, provided the original work is properly cited and the use is non-commercial. See: http://creativecommons.org/ licenses/by-nc/4.0/

(c) Article author(s) (or their employer(s) unless otherwise stated in the text of the article) 2018. All rights reserved. No commercial use is permitted unless otherwise expressly granted.

\section{REFERENCES}

1 Hunter LJ, Dargan PI, Benzie A, et al. Recreational drug use in men who have sex with men (MSM) attending UK sexual health services is significantly higher than in nonMSM. Postgrad Med J 2014;90:133-8.
2 PHE action plan 2015-16 Promoting the health and wellbeing of gay, bisexual and other men who have sex with men: Public Health England, 2015. Report No.: PHE publications gateway number: 2014685

3 McCarty-Caplan D, Jantz I, Swartz J, Msm SJ. MSM and drug use: a latent class analysis of drug use and related sexual risk behaviors. AIDS Behav 2014;18:1339-51.

4 Santos G-M, Coffin PO, Das M, et al. Dose-response associations between number and frequency of substance use and high-risk sexual behaviors among HIV-negative substance-using men who have sex with men (SUMSM) in San Francisco. JAIDS 2013;63:540-4.

5 Sewell J, Miltz A, Lampe FC, et al. Poly drug use, chemsex drug use, and associations with sexual risk behaviour in HIV-negative men who have sex with men attending sexual health clinics. Int I Drug Policy 2017;43:33-43.

6 Ostrow DG, Plankey MW, Cox C, et al. Specific sex drug combinations contribute to the majority of recent HIV seroconversions among MSM in the MACS. J Acquir Immune Defic Syndr 2009:51:349-55.

7 Macdonald N, Elam G, Hickson F, et al. Factors associated with HIV seroconversion in gay men in England at the start of the 21st century. Sex Transm Infect 2008;84:8-13.

8 Hirshfield S, Remien RH, Walavalkar I, et al. Crystal methamphetamine use predicts incident STD infection among men who have sex with men recruited online: a nested case-control study. J Med Internet Res 2004;6:e41.

9 Hegazi A, Lee MJ, Whittaker W, et al. Chemsex and the city: sexualised substance use in gay bisexual and other men who have sex with men attending sexual health clinics. Int J STD AIDS 2017;28:362-6.

10 Bourne A, Weatherburn P. Substance use among men who have sex with men: patterns, motivations, impacts and intervention development need. Sex Transm Infect 2017;93:342-6.

11 Mercer CH, Prah P, Field N, et al. The health and well-being of men who have sex with men (MSM) in Britain: evidence from the third National Survey of Sexual Attitudes and Lifestyles (Natsal-3). BMC Public Health 2016;16:525.

12 Bourne A, Reid D, Hickson F, et al. The Chemsex study, 2014.

13 Weatherburn P, Hickson F, Reid D, et al. Motivations and values associated with combining sex and illicit drugs ('chemsex') among gay men in South London: findings from a qualitative study. Sex Transm Infect 2017;93:203-6.

14 McCall $H$, Adams N, Mason D, et al. What is chemsex and why does it matter? BMJ 2015:351:h5790

15 Frankis J, Clutterbuck D. What does the latest research evidence mean for practitioners who work with gay and bisexual men engaging in chemsex? Sex Transm Infect 2017;93:153-4.

16 Pakianathan MR, Lee MJ, Kelly B, et al. How to assess gay, bisexual and other men who have sex with men for chemsex. Sex Transm Infect 2016;92:568-70.

17 Stuart D, Weymann J. Chemsex and care planning: one year in practice. HIV Nursing Journal 2015;15:24-8.

18 Hockenhull J, Murphy KG, Paterson S. An observed rise in $\gamma$-hydroxybutyrateassociated deaths in London: evidence to suggest a possible link with concomitant rise in chemsex. Forensic Sci Int 2017;270:93-7.

19 Lee M, Hegazi A, Barbour A, et al. 011 Chemsex and the city: sexualised substance use in gay bisexual and other men who have sex with men. Sex Transm Infect 2015;91:A2-4

20 Wiggins H, Mebrahtu H, Sullivan A, et al. P070 'ChemSex' within men who have sex with men (MSM): how big is the problem outside major conurbations?: Abstract P070 Table 1. Sex Transm Infect 2016;92(Suppl 1):A42-3.

21 Government H. Drug Strategy. 2017.

22 Sewell J, Speakman A, Phillips AN, et al. A cross-sectional study on 'Attitudes to and Understanding of Risk of Acquisition of HIV' (AURAH) study: design, methods and participant characteristics. JMIR Res Protoc. In Press. 2015.

23 Sewell J, Speakman A, Phillips AN, et al. Attitudes to and understanding of risk of acquisition of HIV over time: design and methods for an internet-based prospective cohort study among uk men who have sex with men (the AURAH2 Study). JMIR Res Protoc 2016;5:e128.

24 Zou G. A modified Poisson regression approach to prospective studies with binary data. Am J Epidemiol 2004;159:702-6.

25 StataCorp. Stata statistical software: release 13. College Station, TX: StataCorp LP, 2013.

26 Brown AE, Mohammed H, Ogaz D, et al. Fall in new HIV diagnoses among men who have sex with men (MSM) at selected London sexual health clinics since early 2015: testing or treatment or pre-exposure prophylaxis (PrEP)? Eurosurveillance 2017;22.

27 Hammoud MA, Jin F, Degenhardt L, et al. Following Lives Undergoing Change (Flux) study: implementation and baseline prevalence of drug use in an online cohort study of gay and bisexual men in Australia. Int I Drug Policy 2017:41:41-50.

28 Prevention CfDCa. HIV Infection risk, prevention, and testing behaviors among men who have sex with men National HIV behavioral surveillance 20 U.S. Cities, 2014: National HIV Behavioural Surveillance, 2014.

29 Mao L, Adam P, Treloar C, et al. HIV/AIDS, hepatitis and sexually transmissible infections in Australia: annual report of trends in behaviour 2016. Sydney: Centre for Social Research in Health, UNSW, Australia, 2016.

30 Travis Sanchez TF, Drake A, Behel S, et al. Human immunodeficiency virus (HIV) risk, prevention, and testing behaviors — United States, National HIV Behavioral 
Surveillance System: Men Who Have Sex with Men, November 2003-April 2005. The National HIV Behavioral Surveillance (NHBS) System, Prevention CfDCa. 2006.

31 HIV risk, prevention, and testing behaviors National HIV behavioral surveillance system men who have sex with men 20 U.S. Cities, 2011: Centers for Disease Control and Prevention, 2011.
32 Stuart D. Sexualised drug use by MSM: background, current status and response. HIV Nursing 2013;13:1-5.

33 Pines HA, Gorbach PM, Weiss RE, et al. Sexual risk trajectories among MSM in the United States: implications for pre-exposure prophylaxis delivery. J Acquir Immune Defic Syndr 2014;65:579-86. 